\title{
Does Personal Distress Mediate the Effect of Mindfulness on Professional Quality of Life?
}

\author{
Jacky T. Thomas
}

\begin{abstract}
Personal distress is an aspect of the empathy construct which has been negatively associated with a range of psychological and behavioral problems. However, it is unclear whether mindfulness serves to buffer these negative relationships. This study examines direct effects and mediation effects of personal distress and mindfulness among three measures of professional quality of life: compassion fatigue, burnout, and compassion satisfaction. This model was tested using a sample of clinical social workers $(n=171)$. Results indicated that higher personal distress is significantly associated with higher compassion fatigue and burnout and lower compassion satisfaction, while mindfulness is significantly associated with lower compassion fatigue and burnout and higher compassion satisfaction. Mediation analyses showed significant indirect effects on all three measures of professional quality of life, with effect sizes in the small to moderate range. The indirect effects of mindfulness via the personal distress path accounted for 14$22 \%$ of the total effect of mindfulness on the three measures of professional quality of life. Implications for the education and training of social workers are discussed.
\end{abstract}

Keywords: Personal distress, mindfulness, empathy, compassion fatigue, burnout

\section{EMPATHY AND PERSONAL DISTRESS}

\section{Empathy}

Social cognitive psychologist Daniel Batson, one of the most prominent and prolific researchers examining empathy, altruism and the determinants of the urge to help, wrote in 1987, "We psychologists are noted for using our terms loosely and with multiple definitions, but in our use of empathy we seem to have outdone ourselves" (Batson, Fultz, \& Schoenrade, 1987, p. 19). Batson was referring to the divergent definitions of the term empathy, and the consequent difficulty in conducting, reporting, and comparing research. This difficulty with precise definition and labeling continues, and is not limited to the discipline of psychology (see discussion in Batson et al., 1987; Decety, 2011; Eisenberg \& Eggum, 2009; Gerdes, 2011). However, despite significant semantic differences, broad conceptual agreement exists regarding important ideas about empathy. These basic ideas which emerged from social and developmental psychology have been elegantly explicated, reinforced, and enriched by a wealth of sophisticated research emerging from social neuroscience and the neuroimaging techniques currently available.

While it is not possible in this article to detail the full history of empathy research, or to adequately explain many of the important elements of the empathy construct (for excellent reviews see Decety, 2011; Decety \& Meyer, 2008; Eisenberg \& Eggum, 2009; Gerdes, 2011), two ideas are particularly relevant to the research study that will be

Jacky T. Thomas, PhD, is an Assistant Professor of Social Work in the Department of Anthropology, Sociology, and Social Work at Eastern Kentucky University in Richmond, KY. 
reported in this article. The first idea is that empathy should be viewed as a multidimensional process involving both affective and cognitive components. As opposed to the typical lay understanding of the construct, empathy is not just a feeling, a state, or a product. The empathy process begins with an affective response born quite naturally from the biologically based/evolutionally adaptive tendency of one human being to respond to another (emotional resonance). When observing others' behavior, mirror neurons (sensorimotor neurons which respond to behavior that is observed) trigger similar autonomic responses in the observer associated with bodily and facial expressions of the person observed (Decety \& Lamm, 2009). Some degree of affective resonance and emotional involvement is needed for the process of empathy to begin (Eisenberg \& Eggum, 2009), but this initial affective component is then processed cognitively, using differentiated neural circuits and complex "computational processes" (Decety \& Moriguchi, 2009, p. 35). The varied cognitive operations (which follow the initial affective response) optimally allow for a clear sense of self as separate from the person observed, flexible perspective taking, and regulation of emotional responses (Decety, 2011; Decety \& Meyer, 2008; Decety \& Moriguchi, 2009; Singer \& Lamm, 2009). The empathy process is not linear, but occurs in dynamic, iterative, reciprocal feedback loops; the outcome of these processes is variable (Decety, 2011; Singer \& Lamm, 2009).

\section{Personal Distress}

The second idea about which there is broad agreement is that the process of empathy does not always result in pro-social behavior. Among people with certain clinical diagnoses (e.g., persons with autism, or persons with antisocial personality disorder) there may be impaired affective perception or processing, or the use of empathic processes to manipulate or take advantage of others (Decety \& Moriguchi, 2009). However, even among the non-clinical population, the process of empathy does not always result in helping behavior. In fact, some people, upon observing another person who is suffering, experience care and concern for the suffering other, and a consequent urge to help. Others experience personal distress, an aversive reaction to another's pain that is self-focused rather than other-directed and is associated with anxiety, withdrawal, or avoidance rather than an urge to help the suffering person. Unlike the response of care and concern (labeled as empathic concern in this paper), personal distress has been negatively related or unrelated to prosocial behavior (Batson \& Shaw, 1991; Davis, 1983; Decety \& Lamm, 2006; Eisenberg \& Eggum, 2009) .

Different researchers and theorists use a variety of names to describe the otherfocused concern and urge to help, including empathy (Batson et al., 1987; Gerdes \& Segal, 2011); empathic concern (Davis, 1983; Decety \& Lamm, 2009); or sympathy (Eisenberg \& Eggum, 2009; Eisenberg, Wentzel, \& Harris, 1998). However, the term personal distress is fairly consistently used to describe the anxious, self-focused, aversive response experienced by some when witnessing others who are in pain or suffering.

What determines empathic concern or personal distress? A variety of personal, social, and contextual/situational factors may influence the likelihood of an observer experiencing personal distress rather than empathic concern when witnessing the suffering of another. These include the degree to which the observer identifies with the 
suffering person, the meaning assigned to the suffering, the attribution of responsibility for the suffering, and so on (Decety, 2011; Decety \& Lamm, 2009). However, Eisenberg and Eggum (2009) suggest that the strongest predictor of personal distress is high affective arousal and weak emotional regulation. Without adequate regulation of resonant emotional responses when witnessing another's pain or suffering, observers are likely to become over-aroused and experience personal distress, with the consequent urge to turn away or escape the situation. People who do have effective strategies for modulating their vicarious experience of another's distress may be able to stay empathically engaged without experiencing personal distress (Decety \& Lamm, 2009; Eisenberg \& Eggum, 2009).

It is important to emphasize that though the automatic, bottom-up perception of affective states and behavior in others activates similar neural circuits in the observer, this unconscious empathic responding can be influenced by intentional cognitive activity. According to Decety and Lamm (2009), the ability of the observer to use top-down strategies to down-regulate emotional responses is especially important when observed distress is intense or the situation is extreme (pp. 206-207). For social workers and other helping professionals, learning effective skills for preventing and/or managing empathic over-arousal (and the consequent experience of personal distress) may be critical for sustaining effective and satisfying careers in highly stressful human service contexts (e.g., child protection). And for professional training programs, developing strategies for helping students develop and strengthen such skills should be an important goal.

Consequences of personal distress. Empirical studies have shown relationships between personal distress and a host of social and psychological difficulties, including negative verbal and expressive parental behavior with children (Valiente et al., 2004), increased risk of child maltreatment (De Paul, Perez-Albeniz, Guibert, Asla, \& Ormaechea, 2008; Perez-Albeniz \& de Paul, 2003, 2004; Wiehe, 2003), symptoms of psychopathology in children and adults (Psychogiou, Daley, Thompson, \& SonugaBarke, 2008), deficits in effortful control and self-regulation (Eisenberg et al., 1996; Guthrie et al., 1997; Valiente et al., 2004); delinquency and juvenile sex offending (Lindsey, Carlozzi, \& Eells, 2001); lower self-esteem (Joireman, Parrott, \& Hammersla, 2002) lower scores in care-based moral reasoning (Skoe, 2010), more negative perception of students by teachers (Barr, 2011), low emotional regulation and greater negative affect among elderly hospital volunteers (Eisenberg \& Okum, 1996), and lower support among married couples (Devoldre, Davis, Verhofstadt, \& Buysse, 2010).

Personal distress is associated with shame (Joireman, 2004), self-rumination (Joirman, 2004; Jorieman, Parrott, \& Hammersla, 2002) and neuroticism (Mooradian, Davis, \& Matzler, 2011). Higher personal distress scores are found among persons with post-traumatic stress disorder relative to non-traumatized control group participants (Nietlisbach, Maercker, Rossler, \& Haker, 2010) and to depressed patients relative to healthy controls (Thoma et al., 2011). Frequency of clinical errors and speed of recognizing errors in practicing professionals is significantly associated with personal distress (Larson, Fair, Good, \& Baldwin, 2010; West et al., 2006). Professionals higher in personal distress may have more difficulty relating well to clients (Riggio \& Taylor, 
2000). Finally, personal distress is associated with increased compassion fatigue and burnout, and lower compassion satisfaction (Thomas, 2012, in review).

These unhappy associations with personal distress are broad, and probably occur as a result of a combination of high emotional reactivity and deficits in cognitive skills such as flexibility of attention and perspective and capacities for self-regulation of affective responses. It makes sense that helping professional who experience higher personal distress might be more vulnerable to work-related stress reactions such as compassion fatigue and burnout. Understanding factors which contribute to improved flexibility and emotional regulation capacities and reduced personal distress may have important implications for professional quality of life.

\section{Professional Quality of Life}

Work-related stress reactions such as compassion fatigue and burnout negatively influence quality of life for social workers and other helping professionals. Clinical decision making and quality of care provided to clients and may be compromised when workers experience compassion fatigue and/or burnout (Conrad \& Kellar-Guenther, 2006; Huggard, 2003; Killian, 2008; Radey \& Figley, 2007; Valent, 2002). Worker satisfaction and retention in helping professions are also negatively affected (Bride, 2007; DePanfilis, 2006; Figley, 1995; Yankeelov, Barbee, Sullivan, \& Antle 2009). Cunningham (2004) and Bell, Kulkami, and Dalton (2003) speak of the ethical responsibility of employers and educators to address these issues.

Figley (2002) and Stamm (2009) have suggested that the term "compassion fatigue" be used to describe secondary stress reactions among helping professionals who work with traumatized and suffering populations, as it may be a less stigmatizing term than "secondary traumatic stress disorder." Burnout, another negative state often experienced by helping professionals, is generally related more to organizational or institutional factors and is "associated with feelings of hopelessness and difficulties in dealing with work or managing your job effectively" (Stamm, 2005, p. 5). Compassion satisfaction, also an important concept in understanding professional quality of life, refers to the positive feelings of meaning and fulfillment experienced by many practitioners when doing helping work effectively (Stamm, 2005).

Risks and protective factors. Reported rates of compassion fatigue/secondary traumatic stress among helping professionals have varied, with studies showing as many as half (and as few as 13\%) of practitioners affected (Bride, 2007; Conrad \& KellarGuenther, 2006; Sprang, Clark, \& Whitt-Woosley, 2007), while reported rates of burnout are somewhat higher. For example, among mental health workers who provided treatment to the victims of the Oklahoma City bombing, over $41 \%$ were rated as being at high or extremely high risk for burnout (Wee \& Myers, 2002). Siebert (2006) examined a probability sample of 1000 National Association of Social Work members, and found lifetime rates of burnout at $75 \%$, and a current rate of $39 \%$.

Risk and protective factors for compassion fatigue include level of exposure to traumatized clients, social support, supervisory support, and personal coping strategies such as a sense of humor (Bride, 2004); and female gender, caseload percentage of PTSD 
clients, and rural location (Sprang et al., 2007). Regarding burnout, age is a significant predictor of risk; research regarding the effect of gender, however, showed mixed results (Maslach, Schaufeli, \& Leiter, 2001). Though occupational variables traditionally assumed to be important (such as type of caseload and supervision) were significant predictors for burnout in Siebert's (2006) research, she contends that certain personal variables should be examined as well. These include feeling overly responsible for clients and having difficulty asking for help, which her study also showed to be significant predictors of burnout (Siebert, 2006). Sprang and colleagues (2007) found that specialized knowledge and training was associated with higher compassion satisfaction and lower compassion fatigue and burnout among practitioners. While empathy is commonly considered a primary path of vulnerability for the development of secondary stress disorders (Decety \& Lamm, 2006; Figley, 2002; Rothschild, 2006), little empirical research has examined this relationship in light of the multi-dimensional nature of the empathy construct.

What might protect? Most of the studies examining work-stress related problems (secondary traumatic stress, compassion fatigue, and burnout) have examined demographic variables and organizational or institutional factors (such as caseload, training, and supervision, etc.). Fewer studies have looked at intrapersonal factors like empathy or mindfulness which may influence the worker's capacity to sustain an engaged therapeutic presence without falling victim to the negative effects of witnessing the suffering of others (Thomas \& Otis, 2010).

Although epidemiological studies show high rates of professional distress, most helping professionals, even those who work in very high-stress settings, do not experience problematic levels of distress. It is likely that there are multiple factors influencing this differential response to stress, but an examination of the literature regarding resilience indicates that professional training programs should carefully consider their practices regarding clinical training in order to encourage positive coping. Is it possible to develop habits or capacities in students and workers that may have a protective effect on their experience of work-related strain? Are there ways to increase the odds that particular workers/students can remain empathically engaged with clients, but with increased resilience to the potential negative effects of witnessing their clients' pain, and with reduced vulnerability to the patterns of emotional numbing and experiential avoidance that accompany secondary trauma responses? And, is it possible to increase the likelihood that practitioners experience the kinds of work satisfaction associated with longevity in the profession (Yankeelov et al., 2009) and the concomitant accumulation of practice wisdom and experience that no technology can replace?

\section{Mindfulness}

Mindfulness has been defined as "focusing one's attention in a nonjudgmental or accepting way on the experience occurring in the present moment" (Baer, Smith, \& Allen, 2004, p. 191). Secular mindfulness training is increasingly used in clinical settings and is associated with successful intervention with various client populations and problems (see reviews in Baer, 2003; Brown, Ryan \& Creswell, 2007; Chambers, Gullone, \& Allen, 2009; Chiesa \& Serretti, 2009). An increasing number of empirically 
validated clinical approaches include training in mindfulness as a central part of the treatment protocol. These include Dialectical Behavior Therapy (Linehan, 1993), Mindfulness-Based Stress Reduction (Kabat-Zinn, 1990), Mindfulness-Based Cognitive Therapy (Segal, Williams, \& Teasdale, 2002), and Acceptance and Commitment Therapy (Hayes, Strosahl, \& Wilson, 1999).

Not surprisingly, research has emerged which suggests that mindfulness practice offers various benefits to practicing helping professionals, including improved metacognitive abilities and reduced cognitive errors (Epstein, Siegel, \& Silberman, 2008; Ludwig \& Kabot-Zinn 2008); improved affect regulation and stress management (Baer, 2007; Brown \& Ryan, 2003, Creswell, Way, Eisenberger, \& Liebeman, 2007); improved empathetic attunement with clients (Shapiro, Schwartz, \& Bonner, 1998); improved cognitive flexibility (Moore \& Malinowski, 2009); facilitation of positive re-appraisal, in which events are viewed as less negative (Garland, Gaylord, \& Park, 2009); and reduced rumination (Jain et al., 2007). Most relevant to the research reported in this paper are several studies which have found decreases in aspects of burnout after mindfulness interventions with practicing physicians (Krasner et al., 2009) healthcare workers (Galantino, Vaime, Maguire, Szapary, \& Farrar, 2005), and nurses and nursing assistants (Mackenzie, Poulin, \& Steidman-Carlson, 2006). Thomas and Otis (2010) found mindfulness was associated with lower levels of compassion fatigue and burnout among clinical social workers, as well as higher levels of compassion satisfaction.

The qualities (and benefits) associated with mindfulness may be relevant to social workers and other human service providers who are regularly exposed to the suffering of others, often in intense and repeated doses, and who are vulnerable to experiencing personal distress in the absence of sufficient emotional self-regulation strategies

\section{Research Question}

This study examined the relationship between personal distress, mindfulness, and professional quality of life, including compassion fatigue, burnout, and compassion satisfaction, and explored whether personal distress may function as a mediator for the relationship between mindfulness and professional quality of life.

\section{METHODS}

\section{Sample and Procedures}

The study used data from a survey of 400 licensed clinical social workers (LCSWs) in one Midwestern state. The original survey was mailed to 400 LCSWs randomly selected from the list of all (approximately 1600) LCSWs obtained from the State Board of Social Work. In addition, recruitment letters, consent forms, and postage-paid return envelopes were included. One hundred thirty-two usable surveys were returned with the original mailing, and a second mailing resulted in another 39, for a total of 171 , a $42 \%$ response rate. All data were collected between March 8, 2008 and May 29, 2008. The study was approved by the author's university affiliated institutional review board. 
The final sample consisted of 171 Licensed Clinical Social Workers ranging from 31 to 80 years of age $(M=50.34, S D=10.85)$. Eighty-one percent were female $(\mathrm{n}=139)$, with an average of 21.26 years of social work experience $(S D=10.12$, range $=5-53$ years). Almost $85 \%(n=145)$ of the sample reported that they had worked the longest in mental health/substance abuse counseling, with $39.8 \%(\mathrm{n}=68)$ currently working full- or part-time in private practice, $24 \%(n=41)$ in community mental health, and $23 \%(n=40)$ in hospital/medical settings. Approximately $43 \%(\mathrm{n}=71)$ indicated that they had experienced some type of trauma in adulthood, and 55\% $(\mathrm{n}=91)$ reported some childhood trauma history.

\section{Measures}

This study included three established scales measuring professional quality of life (Professional Quality of Life R-IV, Stamm, 2005); aspects of empathy (Interpersonal Reactivity Index, Davis, 1983); and mindfulness (Five Facet Mindfulness Questionnaire, Baer, Smith, Hopkins, Krietemeyer, \& Toney, 2006). In addition, demographic information (age, gender, and years of social work practice experience) and two single item questions inquiring about child and adult trauma histories were included to be used as control variables. Alpha values, means, and standard deviations from the current study for the three scales and/or their relevant subscales are included in Table 1 below. It should be noted that both the Professional Quality of Life Scale (ProQOL) and the Interpersonal Reactivity Index (IRI) are composed of distinct subscales, and are not meant to be used cumulatively; consequently, subscale scores are reported and there is no total score for empathy or for professional quality of life. Finally, since this study only used the total scale on the Five Facet Mindfulness Questionnaire (FFMQ) and not the individual subscales, mindfulness subscale information is not included.

Table 1: $\quad$ Study ProQOL IV-R, IRI (Empathy Subscales), and FFMQ (Mindfulness) Alphas, Means, and Standard Deviations.

\begin{tabular}{lccccc}
\hline \multicolumn{1}{c}{ Scale } & No. of items & Range of scores & Alpha & Mean & $S D$ \\
\hline Professional Quality of Life & & & & & \\
Compassion Fatigue & 10 & $0-50$ & .86 & 11.67 & 7.10 \\
Burnout & 10 & $0-50$ & .78 & 18.80 & 6.56 \\
Compassion Satisfaction & 10 & $0-50$ & .91 & 39.46 & 6.69 \\
Interpersonal Reactivity Index-Empathy & & & & & \\
Empathetic Concern & 7 & $0-28$ & .67 & 20.13 & 3.76 \\
Perspective Taking & 7 & $0-28$ & .75 & 19.39 & 3.86 \\
Fantasy & 7 & $0-28$ & .77 & 12.87 & 5.20 \\
Personal Distress & 7 & $0-28$ & .75 & 7.44 & 4.30 \\
Five Facet Mindfulness Questionnaire & 39 & $39-195$ & .93 & 144.80 & 18.35 \\
\hline
\end{tabular}


Professional quality of life: Compassion fatigue, burnout, and compassion satisfaction. The Professional Quality of Life scale (ProQOL IV-4) is a 30-item selfreport measure with three, distinct 10-item scales measuring compassion fatigue $(\mathrm{CF})$, compassion satisfaction (CS), and burnout (B). Stamm (2005) reported alpha coefficients for the compassion satisfaction, burnout, and compassion fatigue scales as, respectively, $.87, .72$, and .80. Reliability coefficients in this study were .91 for compassion satisfaction, .78 for burnout, and .86 for compassion fatigue. Musa and Hamid (2008) found similar reliability statistics when using the measure with a sample of international aid workers. The ProQOL has been translated to multiple languages and used in various countries and populations, and is one of the measures used by the National Child Traumatic Stress Network (NCTSN, 2011). Response options for each of the thirty items range from 0 (never) to 5 (very often).

Compassion fatigue refers to symptoms (such as intrusive thoughts and images, avoidance of reminders of the stressor, and fearfulness) related to work-related, secondary exposure to very stressful events. Items such as "As a result of my helping, I have intrusive, frightening thoughts" are used to measure the concept of compassion fatigue. Burnout is defined as those symptoms related to difficulties in dealing with work or managing one's job effectively, such as hopelessness, discouragement, and exhaustion. Items such as "Because of my work as a helper, I feel exhausted" are included in the burnout scale. Finally, compassion satisfaction refers to the positive feelings experienced by many practitioners when doing helping work effectively (Stamm, 2005). Questions such as "I get satisfaction from being able to help people" and "I feel invigorated after working with those I help" (Stamm, 2005) explore this sense of accomplishment and positive affect. Possible scores for each of the three 10-item subscales range from 0-50.

Mindfulness. In this study, mindfulness was defined as "focusing one's attention in a nonjudgmental or accepting way on the experience occurring in the present moment" (Baer et al., 2004, p. 191). Baer and colleagues (2006) reviewed the existing literature and completed a factorial analysis of a combined dataset consisting of all items from five existing mindfulness scales. This analysis differentiated five distinct factors of the mindfulness construct which the authors included in the 39-item Five Facet Mindfulness Questionnaire. These include observing, describing, acting with awareness, non-judging of inner experience, and non-reactivity to inner experience. Baer and colleagues (2008) suggest that it is important that researchers be able to investigate particular facets of mindfulness in order to refine the understanding of how specific skills relate to psychological adjustment, but their analysis also supports using the total score to measure the combined, overarching construct of mindfulness. This total score was used in this study, with a possible range of 39-195. Baer and colleagues $(2006,2008)$ report reasonable construct validity, with an alpha coefficient for the total scale of .93. The alpha coefficient for the total scale in this study was also .93. Response options ran from 1 (never or very rarely true) to 5 (very often or always true).

Empathy subscales. Davis's Interpersonal Reactivity Index (IRI) used in this study defines empathy multi-dimensionally as both cognitive and affective reactions of one individual to the experiences of another (Davis, 1983). The IRI consists of four, distinct, seven-item scales measuring different components of dispositional empathy, including 
empathic concern (EC), perspective taking (PT), fantasy (F), and personal distress (PD). The scales are not intended to be used cumulatively (M. Davis, personal communication, April 2, 2010). Response options in the survey instrument range from 0 (does not describe me well) to 4 (does describe me well). The range of scores for each subscale is $0-28$. Davis (1983) conducted validation studies which showed subscale correlations in expected directions with measures of cognitive or affective empathy and with conceptually related measures of social and emotional functioning. Internal consistency was acceptable for each of the four subscales. Davis found Cronbach's alphas which ranged from .71 to .77 ; reliability statistics were somewhat higher in some other studies (Cliffordson, 2002; Pulos, Elison, \& Lennon, 2004). In this study, alpha coefficients were .67 for empathic concern, .75 for perspective taking, .77 for fantasy, and .75 for personal distress.

Davis defined empathic concern as "other oriented feelings of sympathy and concern for unfortunate others" (Davis, 1983, p. 114). This concept was explored with items such as "I am often quite touched by things that I see happen." Perspective taking, "the tendency to spontaneously adopt the psychological point of view of others" (p. 113) included items such as "I sometimes try to understand my friends better by imagining how things look from their perspective." Fantasy, "tendencies to transpose themselves imaginatively into the feelings and actions of fictitious characters in books, movies, and plays" (p. 114) consisted of statements such as "I day dream and fantasize with some regularity about things that might happen to me." Finally, the personal distress subscale, of primary interest in this study, measures, "self-oriented feelings of personal anxiety and unease in tense interpersonal settings" (p. 114) and included items such as "I sometimes feel helpless when I'm in the middle of a very emotional situation" and "I tend to lose control during emergencies."

Control variables. Age (in years), gender, years of practice experience, and selfreported history of trauma in childhood and in adulthood were all included as control variables in this study. The child and adult trauma variables were dummy coded (past history of trauma $=1$ ).

\section{Data Analysis}

After examining zero-order correlations, simultaneous entry Ordinary Least Squares (OLS) regression was used to initially address the research questions and examine associations of control and predictor variables with each of the three outcome variables, compassion fatigue, burnout, and compassion satisfaction. Mindfulness and the four empathy subscales were included in each model. Each model was adjusted with the aforementioned control variables. Following the examination of main effects, hierarchical regression analyses were completed for each of the dependent variables in order to further explicate the relationships between variables. Additional regression analyses were used to explore indirect (mediation) effects, and Sobel tests were used to test for the significance of mediation effects. Data analysis was conducted using PASW Statistics for Windows, Version 18.0. 
While mediation models are designed to be used to explain causal paths with experimental data, they are also commonly used with correlational data for the purposes of theory development (Rucker, Preacher, Tormala, \& Petty, 2011), with the understanding that causality cannot be proved with correlational data. Results simply suggest theoretically coherent and statistically viable paths which then should be tested with experimental designs. Nonetheless, tests for mediation effects in correlational studies can offer important insight about relationships between variables, and provide direction for future research (Rucker et al., 2011). Consequently, the decision was made to use mediation analyses in this study in order to test whether the effect of mindfulness on the dependent variables (compassion fatigue, burnout, and compassion satisfaction) occurs partly through the effect that mindfulness has on personal distress. That is, does mindfulness influence personal distress in a way which then impacts professional quality of life?

\section{RESULTS}

Bivariate correlations. Zero-order correlations (Table 2) showed moderate correlations between mindfulness with all three measures of professional quality of life (compassion fatigue, burnout, and compassion satisfaction) with correlations between .43 and .55 (all at $\mathrm{p}<.001$ ). The personal distress subscale of the empathy construct was significantly correlated with all three dependent variables (Pearson's $r$ ranging from .36.39). Personal Distress was correlated with mindfulness $(-.47, \mathrm{p}<.001)$. In addition, the perspective taking and fantasy (empathy) subscales showed weak but significant correlations with two of three dependent variables, and with mindfulness. Age and work experience were weakly but significantly associated with both burnout and compassion satisfaction.

Regression analyses. Simultaneous-entry OLS regression analyses were run by regressing each of the dependent variables (compassion fatigue, burnout, and compassion satisfaction) on the independent variables (mindfulness and the four empathy subscales) and the control variables (Table 3). In the regressions for compassion fatigue and burnout, personal distress was the only empathy subscale with significant associations, with higher personal distress predicting higher compassion fatigue and burnout. In the regression for compassion satisfaction, higher personal distress predicted lower levels of compassion satisfaction, and higher empathic concern was associated with higher compassion satisfaction. The only control variable significantly associated with any of the dependent variables was female gender, which was associated with higher levels of burnout. Higher mindfulness was moderately associated with lower compassion fatigue and burnout, and higher compassion satisfaction.

When variables are entered into a regression equation sequentially, it is possible to see what each variable or set of variables adds to the predictive power of the model over and above what the previously entered variables have shown (Tabachnick \& Fidell, 2001). Therefore, in order to better understand the relationships between variables, hierarchical regression analyses (using the enter method) were run for each dependent variable (Table 4). The control variables (child and adult trauma histories, age, female gender, and years work experience) were entered first, followed by the four empathy 
Table 2: $\quad$ Zero-Order Correlations for Study Variables

\begin{tabular}{|c|c|c|c|c|c|c|c|c|c|}
\hline Variable & $\mathbf{C F}$ & B & CS & $\mathbf{M}$ & PT & $\mathbf{F}$ & EC & PD & $\mathbf{A}$ \\
\hline (CF) Compassion Fatigue & -------- & & & & & & & & \\
\hline (B) Burnout & $.646^{* *}$ & -------- & & & & & & & \\
\hline (CS) Compassion Satisfaction & $-.368 * *$ & $-.725 * *$ & -------- & & & & & & \\
\hline (M) Mindfulness & $-.429 * *$ & $-.551 * *$ & $.490 * *$ & 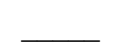 & & & & & \\
\hline (PT) Perspective Taking & -.134 & $-.212 *$ & $.290 * *$ & $.357^{*}$ & --------- & & & & \\
\hline (F) Fantasy & $.211^{*}$ & $.160 *$ & -.096 & $-.227 *$ & -.067 & ------- & & & \\
\hline (EC) Empathic Concern & .125 & .006 & .146 & .004 & $.346^{* *}$ & $.184 *$ & ------ & & \\
\hline (PD) Personal Distress & $.364 * *$ & $.392 * *$ & $-.392 * *$ & $-.471 * *$ & $-.379 * *$ & $.320 * *$ & .005 & ------- & \\
\hline (A) Age & -.074 & $-.210^{*}$ & $.196^{*}$ & $.235^{*}$ & .087 & -.044 & .010 & -.075 & ------- \\
\hline (WE) Work Experience & -.031 & $-.191 *$ & $.178^{*}$ & $.182 *$ & .074 & .015 & -.031 & -.107 & $.746^{* *}$ \\
\hline
\end{tabular}


Table 3: Regression Analysis of Factors Associated with Compassion Fatigue, Burnout, and Compassion Satisfaction

\begin{tabular}{|c|c|c|c|c|c|c|c|c|c|}
\hline & \multicolumn{3}{|c|}{ Compassion Fatigue } & \multicolumn{2}{|c|}{ Burnout } & \multicolumn{4}{|c|}{ Compasssion Satisfaction } \\
\hline & $\begin{array}{l}\text { Unstand- } \\
\text { ardized B }\end{array}$ & $\begin{array}{l}\text { Std. } \\
\text { Error }\end{array}$ & $\boldsymbol{\beta}$ & $\begin{array}{l}\text { Unstand- } \\
\text { ardized B }\end{array}$ & $\begin{array}{l}\text { Std. } \\
\text { Error }\end{array}$ & $\boldsymbol{\beta}$ & $\begin{array}{l}\text { Unstand- } \\
\text { ardized B }\end{array}$ & $\begin{array}{l}\text { Std. } \\
\text { Error }\end{array}$ & $\boldsymbol{\beta}$ \\
\hline Child trauma & -.525 & 1.049 & -.035 & -.313 & .969 & -.024 & -.109 & 1.034 & -.008 \\
\hline Adult trauma & 2.202 & 1.149 & .153 & -.167 & .975 & -.013 & 1.645 & 1.041 & .122 \\
\hline Age & -.042 & .072 & -.063 & -.007 & .061 & -.011 & .006 & .065 & .010 \\
\hline Gender & .503 & 1.414 & .026 & 2.652 & 1.199 & $.154 *$ & -1.552 & 1.282 & -.087 \\
\hline Yrs experience & .074 & .077 & .100 & -.041 & .066 & -.060 & .043 & .071 & .062 \\
\hline Persp. taking & .097 & .159 & .053 & .088 & .136 & .053 & .021 & .145 & .012 \\
\hline Fantasy & .036 & .107 & .026 & .002 & .090 & .002 & .032 & .096 & .025 \\
\hline Emp. concern & .235 & .147 & .113 & -.029 & .127 & -.017 & .282 & .136 & $.160 *$ \\
\hline Pers. distress & .306 & .145 & $.185^{*}$ & .267 & .123 & $.192 *$ & -.350 & .132 & $-.226^{* *}$ \\
\hline Mindfulness & -.131 & .034 & $-.334 * * *$ & -.157 & .029 & $-.447 * * *$ & .133 & .031 & $.365 * * *$ \\
\hline $\mathrm{R}^{2}\left(\right.$ Adj. $\left.\mathrm{R}^{2}\right)$ & \multicolumn{3}{|c|}{$.265(.214)^{* * *}$} & \multicolumn{3}{|c|}{$.353(.309)^{* * *}$} & \multicolumn{3}{|c|}{$.308(.261)^{* * *}$} \\
\hline
\end{tabular}


Table 4: Hierarchical Regression Analyses Showing Associations with Compassion Fatigue, Burnout, and Compassion Satisfaction

\begin{tabular}{|c|c|c|c|c|c|c|c|c|c|}
\hline \multirow[t]{2}{*}{ Models } & \multicolumn{3}{|c|}{ Compassion Fatigue } & \multicolumn{3}{|c|}{ Burnout } & \multicolumn{3}{|c|}{ Compassion Satisfaction } \\
\hline & $\beta$ & $\beta$ & $\beta$ & $\beta$ & $\beta$ & $\beta$ & $\beta$ & $\beta$ & $\beta$ \\
\hline \multicolumn{10}{|l|}{ Model 1: Controls } \\
\hline Ch. Trauma & -.051 & -.055 & -.036 & -.022 & -.052 & -.024 & -.043 & .015 & -.008 \\
\hline Ad. Trauma & $.244 * *$ & $.191 *$ & .153 & .107 & .038 & -.013 & .003 & .081 & .122 \\
\hline Age & -.128 & -.123 & -.063 & -.120 & -.099 & -.011 & .125 & .082 & .010 \\
\hline Gender & .043 & .014 & .026 & .159 & .138 & $.154^{*}$ & -.083 & -.074 & -.087 \\
\hline Wk. Exp. & .080 & .097 & .100 & -.070 & -.064 & -.060 & .057 & .065 & .062 \\
\hline \multicolumn{10}{|l|}{ Model 2: Empathy } \\
\hline Perspective Taking & & -.032 & .053 & & .027 & .002 & & .004 & .025 \\
\hline Fantasy & & .052 & .026 & & .027 & .002 & & .004 & .025 \\
\hline Empathic. Concern & & .146 & .125 & & .016 & -.017 & & .133 & $.160 *$ \\
\hline Personal Distress & & $.301 * * *$ & $.185^{*}$ & & $.348 * * *$ & $.192 *$ & & $-.053 * * *$ & $-.226 * *$ \\
\hline \multicolumn{10}{|c|}{ Model 3: Mindfulness } \\
\hline Mindfulness & & & $-.334 * * *$ & & & $-.447 * * *$ & & & $.365 * * *$ \\
\hline $\mathrm{R}^{2}$ & .062 & .192 & .265 & .082 & .220 & .353 & .045 & .220 & .308 \\
\hline $\mathrm{R}^{2} \Delta$ & .062 & $.130 * * *$ & $.073 * * *$ & $.082 *$ & $.138^{* * *}$ & $.132 * * *$ & .045 & $.175^{* * *}$ & $.088^{* * *}$ \\
\hline \multicolumn{10}{|l|}{ Total Model } \\
\hline $\mathrm{F}$ & & & $5.332 * * *$ & & & $8.067 * * *$ & & & $6.624 * * *$ \\
\hline $\mathrm{R}^{2}\left(\operatorname{Adj} . \mathrm{R}^{2}\right)$ & & & $.265(.215)$ & & & $.353(.309)$ & & & $.308(.261)$ \\
\hline
\end{tabular}


subscales, and finally mindfulness. In each of the three hierarchical regressions, the addition of mindfulness to the equation resulted in a significant reduction in the strength of the relationship between personal distress and the dependent variables, suggesting a possible partial mediation effect.

Mediation. Variables are thought to function as mediators when they "account for the relation between the predictor and the criterion variables... and speak to how and why such effects occur" (Baron \& Kenny, 1986, p. 1176). The hierarchical regression analyses showed that the effect of personal distress on compassion fatigue, burnout, and compassion satisfaction was smaller when mindfulness was included in the equations, supporting the proposed theoretical path from higher mindfulness to lower personal distress to improvements in the three measures of professional quality of life. That is, the results of the hierarchical regressions suggested the possibility that some of the effect that mindfulness has on the dependent variables may occur through its influence on personal distress.

There are four requirements for mediation to be established (Baron \& Kenny, 1986; Preacher \& Leonardelli, 2006): (1) the independent variable must be significantly related to the mediator; (2) the independent variable, without the mediator, must be significantly related to the dependent variable; (3) The mediator significantly affects the dependent variable; and (4) the influence of the independent variable on the dependent variable must be reduced when the mediator is added to the model (Baron \& Kenny, 1986; Preacher \& Leonardelli, 2006). A series of regression analyses were completed, indicating that all four of these requirements were met. Figures 1, 2, and 3 below show standardized beta coefficients $(\beta)$ for the relevant paths, and indicate the difference in the relationship between mindfulness and the three dependent variables with and without controlling for personal distress (direct effect, or $\mathrm{C}_{(\mathrm{dir})}$ and total effect or $\mathrm{C}_{(\mathrm{tot})}$ ).

\section{Figure 1: Compassion Fatigue: Standardized Beta Coefficients}

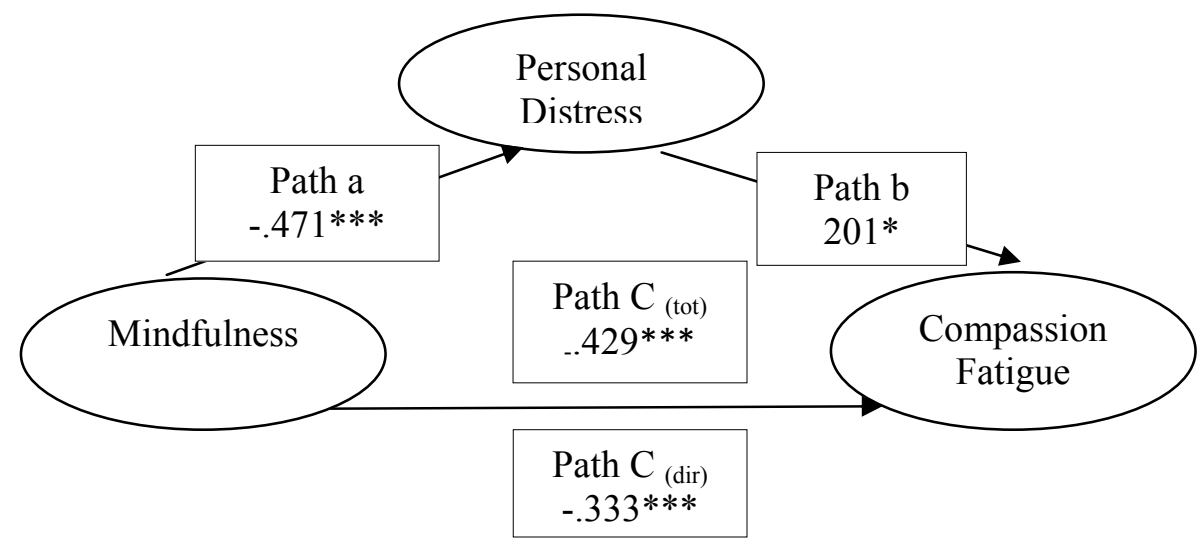

The coefficient above the line from mindfulness to compassion fatigue is for the total path without controlling for personal distress, while the coefficient below the line is for the direct path when personal distress is controlled. The total path minus the direct path equals the indirect path

$* \mathrm{p}>.05 ; * * \mathrm{p}>.01 ; * * * \mathrm{p}>.001$ 
Figure 2: $\quad$ Burnout: Standardized Beta Coefficients

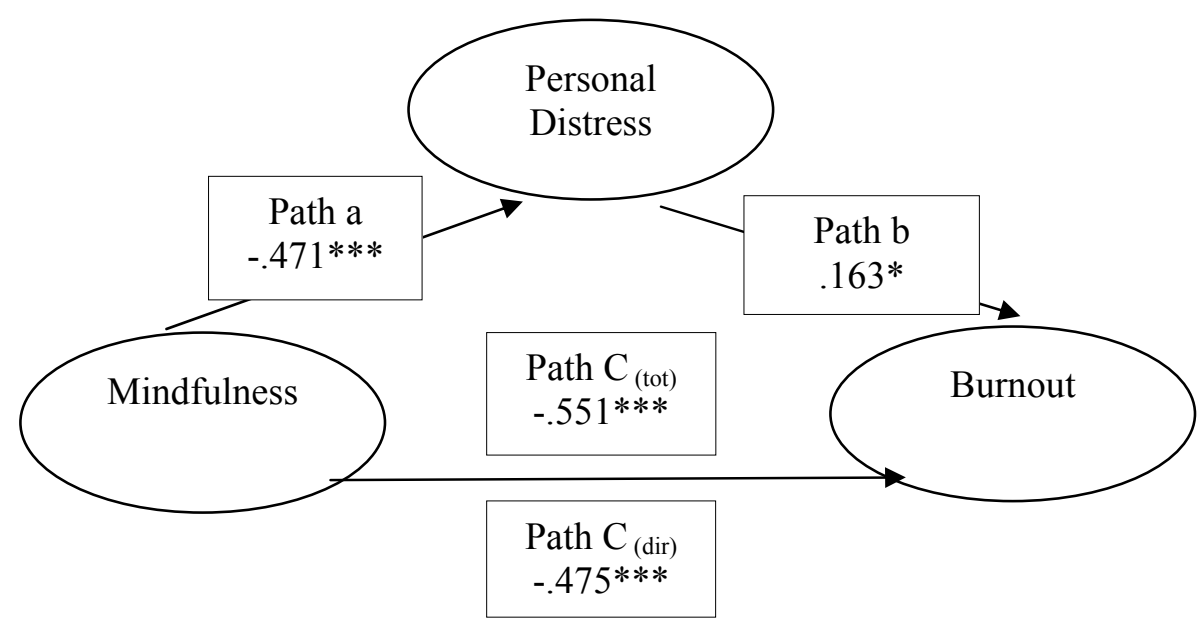

The coefficient above the line from mindfulness to burnout is for the total path without controlling for personal distress, while the coefficient below the line is for the direct path when personal distress is controlled. The total path minus the direct path equals the indirect path.

$* \mathrm{p}>.05 ; * \mathrm{p}>.01 ; * * * \mathrm{p}>.001$

Figure 3: $\quad$ Compassion Satisfaction: Standardized Beta Coefficients

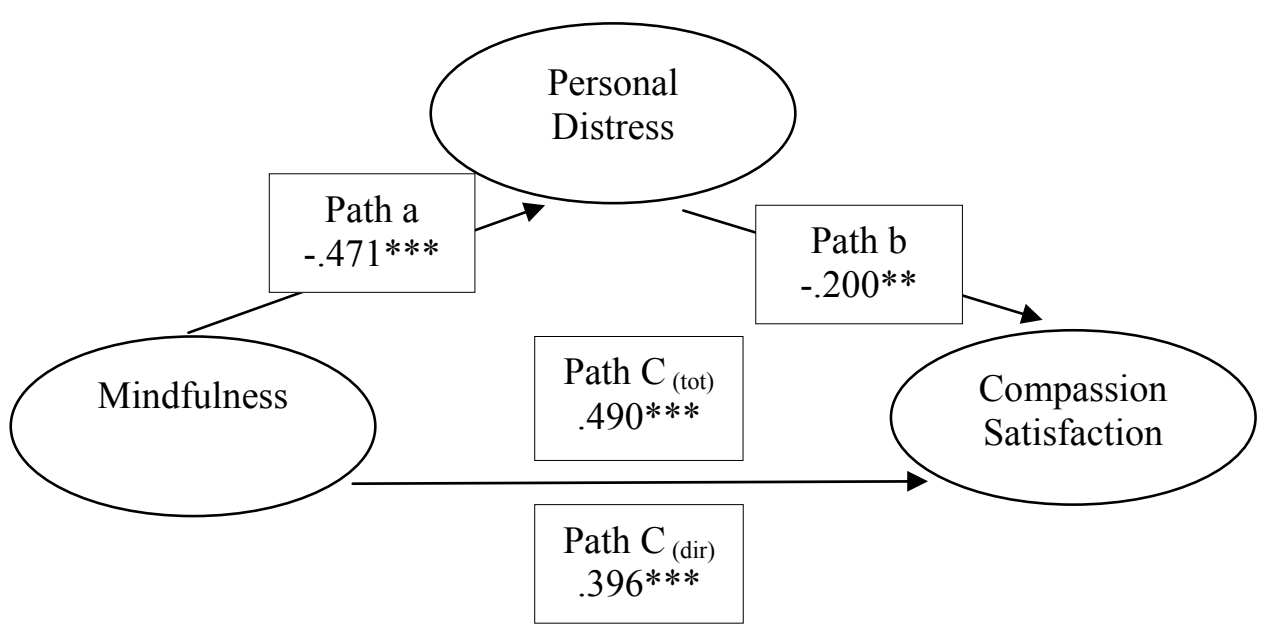

The coefficient above the line from mindfulness to compassion satisfaction is for the total path without controlling for personal distress, while the coefficient below the line is for the direct path when personal distress is controlled. The total path minus the direct path equals the indirect path.

$* \mathrm{p}>.05 ; * * \mathrm{p}>.01 ; * * * \mathrm{p}>.001$ 
An online Sobel test calculator was then used to assess the significance of the mediation effect (Preacher \& Leonardelli, 2006). The calculator uses the unstandardized regression coefficients for the association between the independent variable and the mediator, $(a)$; the unstandardized coefficient for the association between the mediator and the dependent variable $(b)$, controlling for the independent variable; and finally the standard error of both of these coefficients. The calculator performs three versions of mediation tests, the Sobel, Aroian, and Goodman tests for significance of mediation. Results of the three tests are similar, and in this study the Sobel test statistics are reported as the Sobel test generally is considered to be a very conservative measure of mediation (Kenny, 2012). All of the Sobel tests were significant, indicating that personal distress partially mediates the relationship between mindfulness and all three dependent variables (see Table 5, below).

In each of the three figures above, path a is the standardized regression coefficient $(\beta)$ for the path between mindfulness and personal distress; and path $\mathrm{b}$ is the standardized regression coefficient $(\beta)$ for the path between personal distress and the relevant outcome variable (compassion fatigue, burnout, or compassion fatigue) controlling for mindfulness. Path $\mathrm{C}_{\text {(tot) }}$ shows the total effect of mindfulness on the outcome variables, (without controlling for the mediation path), while path $\mathrm{C}_{\text {(dir) }}$ shows the direct effect of mindfulness on the outcome variable with the indirect path partialed out.

Table 5: Mediation of Relationship of Mindfulness with Compassion Fatigue, Burnout, and Compassion Satisfaction by Personal Distress

\begin{tabular}{lcccccc}
\hline $\begin{array}{l}\text { Dependent } \\
\text { Variable }\end{array}$ & $\begin{array}{c}\text { Mediator/Independent } \\
\text { Variable }\end{array}$ & $a$ & SE $a$ & $b$ & SE $b$ & Sobel $(p)$ \\
\hline $\begin{array}{l}\text { Compassion } \\
\text { Fatigue }\end{array}$ & $\begin{array}{c}\text { Mindfulness/ Personal } \\
\text { Distress }\end{array}$ & -.111 & .016 &. .328 & .128 & $-2.404(\mathrm{p}<.05)$ \\
Burnout & $\begin{array}{c}\text { Mindfulness/ Personal } \\
\text { Distress }\end{array}$ & -.111 & .016 & -.245 & .110 & $-2.121(\mathrm{p}<.05)$ \\
$\begin{array}{l}\text { Compassion } \\
\text { Satisfaction }\end{array}$ & $\begin{array}{c}\text { Mindfulness/ Personal } \\
\text { Distress }\end{array}$ & -.111 & .016 & -.310 & .116 & $2.494(\mathrm{p}<.05)$ \\
\hline
\end{tabular}

$\mathrm{a}=$ unstandardized regression coefficient of IV \& mediator; Sea $=$ standard error of $\mathrm{a} ; \mathrm{b}=$ unstandardized regression coefficient of mediator \& DV, controlling for IV; SEb = standard error of $b$; Sobel $(\mathrm{p})=$ Sobel test statistic and $p$ value

Kenny (2012) suggests two ways to measure mediation, the total indirect effect (the mediation path), and the proportion of total effect mediated. The total indirect effect is measured alternately as the difference between the total effect, $\mathrm{C}_{(\text {tot) }}$, and the direct effect, $\mathrm{C}_{\text {(dir) }}$, or as the product of paths a and $\mathrm{b}$. The total indirect effect was .096 for compassion fatigue; .077 for burnout; and .094 for compassion satisfaction. While these are very small effects according to the usual Cohen (1988) standards, Kenny (2012) and Preacher and Kelley (2011) suggest that because this indirect effect is actually a product of two effects (path a x path b), Cohen's (1988) standards of .1 for small, .3 for medium and .5 
for large effects should be squared, as they are in calculating effect sizes for $\mathrm{r}^{2}$, resulting in effect sizes of .01 for small effects, .09 for medium, and .25 for large. According to this measure, the effect sizes are in the small to medium range for the indirect effects.

The second commonly used effect size measure in mediation analysis is the proportion of the total effect, $\mathrm{C}_{\text {(tot) }}$ that is mediated (Kenny, 2012; MacKinnon, Fairchild, $\&$ Fritz, 2007). This measure is usually expressed as a ratio of indirect effect over total effect (indirect effect divided by the total effect). According to this formula, the percentage of the total effect of mindfulness on compassion fatigue explained by the mediating effect of personal distress is $22 \%$, for burnout, $14 \%$; and for compassion satisfaction, $19 \%$. That is, about a fifth of the total beneficial effect mindfulness has on compassion fatigue, burnout, and compassion satisfaction is due to the positive influence mindfulness has on personal distress.

\section{DISCUSSION}

In this study, higher levels of personal distress were associated with higher compassion fatigue and burnout, and lower compassion satisfaction, while higher mindfulness was associated with lower compassion fatigue and burnout, and higher compassion satisfaction. Mindfulness had an inverse relationship with personal distress. The negative influence of personal distress on compassion fatigue, burnout, and compassion satisfaction was significantly lower when mindfulness was included in the model. These results suggest that mindfulness may be an important construct in understanding ways to mitigate the negative effects of the naturally-occurring experience of personal distress on professional quality of life among social workers and other helpers.

A broad array of benefits seems to occur as a result of mindfulness practice. However, understanding the processes and mechanisms that result in these beneficial effects is important in order to focus research and target change strategies. Mediation analysis allows us to explore these processes and mechanisms and move from "merely descriptive to more functional understanding of the relationships among variables" (Preacher \& Hayes, 2004, p. 720).

Empathy has been called a "double-edged sword" because of the potential for harm to the empathizer from frequent or intense empathic encounters (Decety, 2011; Figley, 2002). Results in this study, however, suggest that it is the aspect of empathy labeled as personal distress which may result in harmful effects for practitioners. Successfully negotiating the complex, multi-dimensional process of empathy with the outcome of empathic concern rather than personal distress requires several things, including a capacity to remain differentiated from the person observed, flexibility of attention and perspective, and the ability to intentionally regulate emotional reactivity (Decety \& Lamm, 2009). Mindfulness may contribute to reduced personal distress and improved resilience and quality of life by influencing all of these processes. And, importantly, mindfulness is a skill which can be learned, with benefits that increase with practice (Baer et al., 2006). 
Social workers and other helping professionals are regularly in situations where they are witness to the suffering of others. Their ability to stay empathically engaged is critical to effective practice, yet when the empathy process results in personal distress, practitioners are more likely to disengage or turn away (in one form or another) in order to protect themselves. The existing literature already makes a strong case for the potential benefits of mindfulness training for social workers and other helping professionals; this current study has specific implications regarding the potential for mindfulness to have a protective effect on professional quality of life for practitioners. It may be that mindfulness may assist practitioners to better manage their own reactivity to stressful work experiences and allow for increased intentional top-down management of bottom up emotional responses, resulting in lower personal distress and improved professional quality of life. Although correlational data cannot prove causality, these results suggest a theoretically coherent path by which the beneficial effects of mindfulness on professional quality of life may be partially explained. However, alternate methods to examine causal paths such as structural equation modeling which would better handle measurement error, allow for a clearer examination of the proposed mediation model, and allow for comparison with other possible explanatory models should be considered in future studies.

\section{Limitations}

This research has several limitations, including the limited sample and the $42 \%$ response rate on the original survey. It is also important to acknowledge as a limitation the lack of agreement among researchers regarding precise operational definitions of the constructs of empathy and mindfulness, and the sometimes inconsistent measurement of those constructs. Researchers also disagree regarding the best methods for determining and reporting effect sizes in mediation models (Hayes, 2009; MacKinnon et al., 2007; Preacher \& Kelley, 2011), and criticisms of both the total indirect effect method (deHeuse, 2012) and the total effect mediated method (MacKinnon et al., 2007) exist. Finally, as mentioned above, mediation analyses on cross-sectional data can only point out possible causal paths, not prove them. The cross-sectional research design in this study precludes any determination of causality; it is possible that various other models could also result in statistically significant mediation effects. The ordering of variables in this model is based on theory and suggest possible causal paths, but must be verified with research using experimental designs. Future studies should consider using alternate analytical methods such as structural equation modeling which, as mentioned above, would better handle measurement error and allow for testing multiple models.

\section{References}

Baer, R. A. (2003). Mindfulness training as a clinical intervention: A conceptual and empirical review. Clinical Psychology: Science and Practice, 10(2), 125-143. doi:10.1093/clipsy.bpg015

Baer, R. A. (Ed.). (2007). Mindfulness-based treatment approaches: Clinician's guide to evidence base and applications. Burlington, MA: Elsevier, Inc. 
Baer, R. A., Smith G. T., \& Allen, K. B. (2004). Assessment of mindfulness by selfreport: The Kentucky Inventory of Mindfulness Skills. Assessment, 11, 191-206.

Baer, R. A., Smith, G.T., Hopkins, J., Krietemeyer, J., \& Toney, L. (2006). Using selfreport assessment methods to explore facets of mindfulness. Assessment, 13(1), 2745. doi:10.1177/1073191105283504

Baer, R. A., Smith, G.T., Lykins, E., Button, D., Krietemeyer, J., Sauer, S., ...Williams, J. M. G. (2008). Construct validity of the Five Facet Mindfulness Questionnaire in meditating and nonmeditating samples. Assessment, 15, 329-342. doi:10.1177/1073191107313003

Baron, R. M., \& Kenny, D. A. (1986). The moderator-mediator variable distinction in social psychological research: Conceptual, strategic, and statistical considerations. Journal of Personality and Social Psychology, 51(6), 1173-1182. doi:10.1037/00223514.51.6.1173

Barr, J. J. (2011). The relationship between teachers' empathy and perceptions of school culture. Educational Studies, 37(3), 365-369. doi:10.1080/03055698.2010.506342

Batson, C., Fultz, J., \& Schoenrade, P. A. (1987). Distress and empathy: Two qualitatively distinct vicarious emotions with different motivational consequences. Journal of Personality, 55(1), 19-39. doi:10.1111/1467-6494.ep8970569

Batson, C. D., \& Shaw, L. L. (1991). Evidence for altruism: Toward a pluralism of prosocial motives. Psychological Inquiry, 2(2), 107-122.

Bell, H., Kulkarni, S., \& Dalton, L. (2003). Organizational prevention of vicarious trauma. Families in Society, 84(4), 463-470. doi:10.1606/1044-3894.131

Bride, B. (2004). The impact of providing psychosocial services to traumatized populations. Stress, Trauma, and Crises, 7, 29-46. doi:10.1080/15434610490281101

Bride, B. (2007). Prevalence of secondary traumatic stress among social workers. Social Work, 52(1), 63-70.

Brown, K. W., \& Ryan, R. M. (2003). The benefits of being present: Mindfulness and its role in psychological well-being. Journal of Personality and Social Psychology, 84, 822-848. doi:10.1037/0022-3514.84.4.822

Brown, K. W., Ryan, R. M., \& Creswell, J. D. (2007). Mindfulness: Theoretical foundations and evidence for its salutary effects. Psychological Inquiry, 18(4), 311237. http://tinyurl.com/2837wo2

Chambers, R., Gullone, E., \& Allen, N. B. (2009). Mindful emotion regulation: An integrative review. Clinical Psychology Review, 29, 560-572. doi:10.1016/j.cpr.2009.06.005

Chiesa, A., \& Serretti, A. (2009). Mindfulness-based stress reduction for stress management in healthy people: A review and meta-analysis. Journal of Alternative and Complementary Medicine, 15(5), 593-600. doi:10.1089/acm.2008.0495 
Cliffordson, C. (2002). The hierarchical structure of empathy: Dimensional organization and relation to social functioning. Scandinavian Journal of Psychology, 43, 49-57. doi:10.1111/1467-9450.00268

Cohen, J. (1988). Statistical power analysis for the behavioral sciences $\left(2^{\text {nd }} \mathrm{ed}.\right)$. Hillsdale, NJ: Lawrence Erlbaum Associates.

Conrad, D., \& Kellar-Guenther, Y. (2006). Compassion fatigue, burnout, and compassion satisfaction among Colorado child protection workers. Child Abuse and Neglect, 30, 1071-1080. doi:10.1016/j.chiabu.2006.03.009

Creswell, J., Way, B. M., Eisenberger, N., \& Lieberman, M. (2007). Neural correlates of dispositional mindfulness during affect labeling. Psychosomatic Medicine, 69(6), 560-565. doi:10.1097/PSY.0b013e3180f6171f

Cunningham, M. (2004). Teaching social workers about trauma: Reducing the risks of vicarious traumatization in the classroom. Journal of Social Work Education, 40(2), 305-321.

Davis, M. H. (1983). Measuring individual differences in empathy: Evidence for a multidimensional approach. Journal of Personality and Social Psychology, 44(1), 113126.

Decety, J. (2011). Dissecting the neural mechanisms mediating empathy. Emotion Review, 3(1), 92-108. doi:10.1177/1754073910374662

Decety, J., \& Lamm, C. (2006). Human empathy through the lens of social neuroscience. The Scientific World Journal, 6, 1146-1163. doi:10.1100/tsw.2006.221

Decety, J., \& Lamm, C. (2009). Empathy versus personal distress: Recent evidence from social neuroscience. In J. Decety \& W. Ickes (Eds.), The social neuroscience of empathy (pp. 199-213). Cambridge, MA: The MIT Press.

Decety, J., \& Meyer, M. (2008). From emotion resonance to empathic understanding: A social developmental neuroscience account. Development and Psychopathology, 20(4), 1053-1080. doi:10.1017/S0954579408000503

Decety, J., \& Moriguchi, Y. (2007). The empathic brain and its dysfunction in psychiatric populations; Implications for intervention across different clinical conditions. BioPsychoSocial Medicine, 1, 22-43.

Deheuse, P. (2012). R squared effect-size measures and overlap between direct and indirect effect in mediation analysis. Behavior Research Methods, 44(10), 213-221. doi:10.3758/s13428-011-0141-5

DePanfilis, D. (2006). Invited commentary - Compassion fatigue, burnout, and compassion satisfaction: Implications for retention of workers. Child Abuse \& Neglect, 30(10), 1067-1069. doi:10.1016/j.chiabu.2006.08.002

De Paúl, J., Pérez-Albéniz, A., Guibert, M., Asla, N., \& Ormaechea, A. (2008). Dispositional empathy in neglectful mothers and mothers at high risk for child physical abuse. Journal of Interpersonal Violence, 23(5), 670-684. 
Devoldre, I., Davis, M. H., Verhofstadt, L. L., \& Buysse, A. (2010). Empathy and social support provision in couples: Social support and the need to study the underlying processes. Journal of Psychology, 144(3), 259-284.

Eisenberg, N., \& Eggum, N. D. (2009). Empathic responding: Sympathy and personal distress. In J. Decety \& W. Ickes (Eds.), The social neuroscience of empathy (pp. 7183). Cambridge, Massachusetts: The MIT Press.

Eisenberg, N., Fabes, R. A., Murphy, B., Karbon, M., Smith, M., \& Maszk, P. (1996). The relations of children's dispositional empathy-related responding to their emotionality, regulation, and social functioning. Developmental Psychology, 32, $195-$ 209.

Eisenberg, N., \& Okun, M. A. (1996). The relations of dispositional regulation and emotionality to elders' empathy-related responding and affect while volunteering. Journal of Personality, 64(1), 157-183. doi:10.1111/1467-6494.ep9606210697

Eisenberg, N., Wentzel, N. M., \& Harris, J. D. (1998). The role of emotionality and regulation in empathy-related responding. School Psychology Review, 27(4), 506572.

Epstein, R. M., Siegel, D. J., \& Silberman, J. (2008). Self-monitoring in clinical practice: A challenge for medical educators. Journal of Continuing Education in the Health Professions, 28(1), 5-13. doi:10.1002/chp.149

Figley, C. R. (1995). Compassion fatigue: Toward a new understanding of the costs of caring. In B. H. Stamm (Ed.), Traumatic stress: Self-care issues for clinicians, researchers, \& educators (pp. 3-28). Baltimore, MD: Sidran Press.

Figley, C. R. (2002). Compassion fatigue: Psychotherapists' chronic lack of self care. JCLP/In Session: Psychotherapy in Practice, 58(11), 1433-1441. doi:10.1002/jclp.10090

Galantino, M. L., Vaime, M., Maguire, M., Szapary, P., \& Farrar, J. (2005). Short communication: Association of psychological and physiological measures of stress in health-care professionals during an 8-week mindfulness meditation program: Mindfulness in practice. Stress and Health, 21, 255-261. doi:10.1002/smi.1062

Garland, E. L., Gaylord, S., \& Park, J. (2009). The role of mindfulness in positive reappraisal. Explore (NY), 5(1), 37-44.

Gerdes, K. E. (2011). Empathy, sympathy, and pity: 21st-century definitions and implications for practice and research. Journal of Social Service Research, 37(3), 230-241. doi:10.1080/01488376.2011.564027

Gerdes, K. E., \& Segal, E. (2011). Importance of empathy for social work practice: Integrating new science. Social Work, 56(2), 141-148.

Guthrie, I. K., Eisenberg, N., Fabes, R. A., Murphy, B. C., Holmgren, R., Mazsk, P., \& Suh, K. (1997). The relations of regulation and emotionality to children's situational empathy-related responding. Motivation \& Emotion, 21(1), 87-108. 
Hayes, A. F. (2009). Beyond Baron and Kenny: Statistical mediation analysis in the new millennium. Communication Monographs, 76(4), 408-420.

doi:10.1080/03637750903310360

Hayes, S. C., Strosahl, K., \& Wilson, K. G. (1999). Acceptance and commitment therapy. New York: Guilford Press.

Huggard, P. (2003). Compassion fatigue: How much can I give? Medical Education, 37, 163-164.

Jain, S., Shapiro, S. L., Swanick, S., Roesch, S. C., Mills, P. J., Bell, I., et al. (2007). A randomized controlled trial of mindfulness meditation versus relaxation training: Effects on distress, positive states of mind, rumination, and distraction. Annals of Behavioral Medicine, 33(1), 11-21

Joireman, J. (2004). Empathy and the self-absorption paradox II: Self-rumination and self-reflection as mediators between shame, guilt, and empathy. Self \& Identity, 3(3), 225-238. doi:10.1080/13576500444000038

Joireman, J. A., Parrott III, L., \& Hammersla, J. (2002). Empathy and the self-absorption paradox: Support for the distinction between self-rumination and self-reflection. Self \& Identity, 1(1), 53-65. doi:10.1080/152988602317232803

Kabat-Zinn, J. (1990). Full catastrophe living: Using the wisdom of your body and mind to face stress, pain, and illness. New York: Dell Publishing.

Kenny, D. (2012). Mediation. Retrieved from http://davidakenny.net/cm/mediate.htm\#WIM

Killian, K. D. (2008). Helping till it hurts? A multimethod study of compassion fatigue, burnout, and self-care in clinicians working with trauma survivors. Traumatology, 14(2) 32-44.

Krasner, M. S., Epstein, R. M., Beckman, H., Suchman, A. L., Chapman, B., ...\& Quill, T. E. (2009). Association of an educational program in mindful communication with burnout, empathy, and attitudes among primary care physicians. Journal of the American Medical Association, 302(12), 1284-1293.

Larson, M. J., Fair, J. E., Good, D. A., \& Baldwin, S. A. (2010). Empathy and error processing. Psychophysiology, 47(3), 415-424. doi:10.1111/j.14698986.2009.00949.x

Lindsey, R. E., Carlozzi, A. F., \& Eells, G. T. (2001). Differences in the dispositional empathy of juvenile sex offenders, non-sex-offending delinquent juveniles, and nondelinquent juveniles. Journal of Interpersonal Violence, 16(6), 510-552.

Linehan, M. M. (1993). Cognitive-behavioral treatment of borderline personality disorder. New York: Guilford Press.

Ludwig, D. S., \& Kabat-Zinn, J. (2008). Mindfulness in medicine. Journal of the American Medical Association, 300(11), 1350-1352. doi:10.1001/jama.300.11.1350 
Mackenzie, C. S., Poulin, P. A., \& Steidman-Carlson, R. (2006). A brief mindfulnessbased stress reduction intervention for nurses and nurse aides. Applied Nursing Research, 19(2), 105-109.

MacKinnon, D., Fairchild, A., \& Fritz, M. (2007). Mediation analysis. Annual Review of Psychology, 58, 593-614. doi: 10.1146/annurev.psych58.110405.085542.

Maslach, C., Schaufeli, W. B., \& Leiter, M. P. (2001). Job burnout. Annual Review of Psychology, 52, 397-442. doi:10.1146/annurev.psych.52.1.397

Moore, A., \& Malinowski., P. (2009). Meditation, mindfulness, and cognitive flexibility. Consciousness and Cognition, 18, 176-186. doi:10.1016/j.concog.2008.12.008

Mooradian, T. A., Davis, M., \& Matzler, K. K. (2011). Dispositional empathy and the hierarchical structure of personality. American Journal of Psychology, 124(1), 99109.

Musa, S. A., \& Hamid, A. R. M. (2008). Psychological problems among aid workers operating in Darfur. Social Behavior and Personality, 36(3), 407-416.

National Child Traumatic Stress Network, Secondary Traumatic Stress Committee. (2011). Secondary traumatic stress: A fact sheet for child-serving professionals. Los Angeles, CA, and Durham, NC: National Center for Child Traumatic Stress. Retrieved from http://www.nctsn.org/sites/default/files/assets/pdfs/secondary traumatic tress.pdf

Nietlisbach, G., Maercker, A., Rössler, W., \& Haker, H. (2010). Are empathic abilities impaired in posttraumatic stress disorder? Psychological Reports, 106(3), 832-844. doi:10.24661PRO.106.3.832-844

Perez-Albeniz, A. A., \& de Paul, J. (2003). Dispositional empathy in high- and low-risk parents for child physical abuse. Child Abuse \& Neglect, 27(7), 769-780. doi:10.1016/S0145-2134(03)00111-X

Perez-Albeniz, A. A., \& de Paul, J. (2004). Gender differences in empathy in parents at high- and low-risk of child physical abuse. Child Abuse \& Neglect, 28(3), 289-300. doi:10.1016/j.chiabu.2003.11.017

Preacher, K., \& Hayes, A. (2004). SPSS and SAS procedures for estimating indirect effects in simple mediation models. Behavior Research Methods, 36(4), 717-731. doi:10.3758/BF03206553

Preacher, K., \& Kelley, K. (2011). Effect size measures for mediation models: Quantitative strategies for communicating indirect effects. Psychological Methods, 16(2), 93-115. doi:10.1037/a0022658

Preacher, K. J., \& Leonardelli, G. J. (2006). Calculation for the Sobel test: An interactive calculation tool for mediation tests. Retrieved from http:/quantpsy.org/sobel/sobel.htm

Psychogiou, L., Daley, D., Thompson, M. J., \& Sonuga-Barke, E. S. (2008). Parenting empathy: Associations with dimensions of parent and child psychopathology. British 
Journal of Developmental Psychology, 26(2), 221-232. doi:10.1348/02615100X238582

Pulos, S., Elison, J., \& Lennon, R. (2004). Hierarchical structure of the Interpersonal Reactivity Index. Social Behavior and Personality, 32(4), 355-360. doi:10.2224/sbp.2004.32.4.355

Radey, M., \& Figley, C. (2007). The social psychology of compassion. Clinical Social Work Journal, 35, 207-214. doi:10.1007/s10615-007-0087-3

Riggio, R. E., \& Taylor, S. J. (2000). Personality and communication skills as predictors of hospice nurse performance. Journal of Business \& Psychology, 15(2), 351-359.

Rothschild, B. (2006). Help for the helper: The psychophysiology of compassion fatigue and vicarious trauma. New York: W. W. Norton.

Rucker, D., Preacher, K., Tormala, Z., \& Petty, R. (2011). Mediation analysis in social psychology: Current practices and new recommendations. Social and Personality Psychology Compass, 5/6, 359-371. doi:10.1111/j.1751-9004.2011.00355x

Segal, Z. V., Williams, J. M. G., \& Teasdale, J. D. (2002). Mindfulness-based cognitive therapy for depression: A new approach to preventing relapse. New York: Guilford Press.

Shapiro, S., Schwartz, G., \& Bonner, G. (1998). Effects of mindfulness-based stress reduction on medical and premedical students. Journal of Behavioral Medicine, 21(6), 581-599. doi:10.1023/A:1018700829825

Siebert, D. C. (2006). Personal and occupational factors in burnout among practicing social workers: Implications for researchers, practitioners, and managers. Journal of Social Service Research, 32(2), 25-44. doi:10.1300/J079v32n02_02

Singer, T., \& Lamm, C. (2009). The social neuroscience of empathy. The Year in Cognitive Neuroscience: Annals of the New York Academy of Science, 1156, 81-96. doi:10.1111/j.1749-6632.2009.04118.x

Skoe, E. A. (2010). The relationship between empathy-related constructs and care-based moral development in young adulthood. Journal of Moral Education, 39(2), 191-211. doi:10.1080/03057241003754930

Sprang, G., Clark, J., \& Whitt-Woosley, A. (2007). Compassion fatigue, compassion satisfaction, and burnout: Factors impacting a professional's quality of life. Journal of Loss and Trauma, 12, 259-280. doi:10.1080/15325020701238093

Stamm, B. H. (2005). The professional quality of life scale: Compassion satisfaction, burnout \& compassion fatigue/secondary trauma scales. Lutherville, MD: Sidran Press. Retrieved from http://www.isu.edu/irh/documents/proqol/ProQOL_Manual.pdf

Stamm, B. H. (2009). The concise ProQOL manual. Pocatello, ID: The ProQOL.org. Retrieved from http://www.proqol.org/uploads/ProQOL_Concise 9-2009.pdf 
Tabachnick, B. G., \& Fidell, L. S. (2001). Using multivariate statistics $\left(4^{\text {th }}\right.$ ed.). Needham Heights, MA: Allyn \& Bacon.

Thoma, P., Zalewski, I., von Reventlow, H., Norra, C., Juckel, G., \& Daum, I. (2011). Cognitive and affective empathy in depression linked to executive control. Psychiatry Research, 189(3), 373-378. doi:10.1016/j.psychres.2011.07.030.

Thomas, J. (2012). Association of personal distress with burnout and compassion fatigue among clinical social workers. Unpublished manuscript.

Thomas, J. T., \& Otis, M. D. (2010). Intrapsychic predictors of professional quality of life: Mindfulness, empathy, and emotional separation. Journal of the Society for Social Work and Research, 1(2), 83-98. doi:10.5234/jsswr.2010.7.

Valent, P. (2002). Diagnosis and treatment of helper stresses, traumas, and illnesses. In C. R. Figley (Ed.), Treating compassion fatigue (pp. 17-38). New York: BrunnerRoutledge.

Valiente, C., Eisenberg, N., Fabes, R. A., Shepard, S. A., Cumberland, A., \& Losoya, S. H. (2004). Prediction of children's empathy-related responding from their effortful control and parents' expressivity. Developmental Psychology, 40(6), 911-926. doi:10.1037/0012-1649.40.6.911

Wee, D. F., \& Myers, D. (2002). Stress responses of mental health workers following disaster: The Oklahoma City bombing. In C. R. Figley (Ed.), Treating compassion fatigue (pp. 57-84). New York: Brunner-Routledge.

West, C. P., Huschka, M. M., Novotny, P. J., Sloan, J. A., Kolars, J. C., Habermann, T. M., \& Shanafelt, T. D. (2006). Association of perceived medical errors with resident distress and empathy. JAMA: Journal of the American Medical Association, 296(9), 1071-1078.

Wiehe, V. R. (2003). Empathy and narcissism in a sample of child abuse perpetrators and a comparison sample of foster parents. Child Abuse \& Neglect, 27(5), 541-555. doi:10.1016/S0145-2134(03)00034-6

Yankeelov, P. A., Barbee, A. P., Sullivan, D., \& Antle, P. F. (2009). Individual and organizational factors in job retention in Kentucky's child welfare agency. Children and Youth Services Review, 31, 547-554. doi:10.1016/j.childyouth.2008.10.014

\section{Author note}

Address correspondence to: Jacky T. Thomas, Ph.D., Department of Anthropology, Sociology, and Social Work, Eastern Kentucky University, 521 Lancaster Ave, Richmond, KY 40475. Email: jacky.thomas@eku.edu 